\title{
Successful percutaneous computed tomography guided drainage of mediastinal abscess in esophageal perforation
}

\author{
Azka Latif*, Mohammad Selim, Vikas Kapoor, Mahmoud Ali, Mohsin Mansoor Mirza, \\ Joseph M Stavas
}

CHI Health, Creighton University, Omaha, NE, USA.

\begin{abstract}
Summary Esophageal perforation with subsequent development of a mediastinal abscess is a well-known clinical entity. Etiologies including idiopathic and iatrogenic with invasive procedures have been reported in medical literatures. This condition is seriously associated with high co-morbidity and in some cases especially if intervention has not been applied associated with high mortality. For long time, open surgical intervention was the only available treatment modality for esophageal perforation with subsequent development of a mediastinal abscess. However, recently there are some other less invasive modalities that have been used with comparable if not preferable success including; self-expandable metallic or plastic stents and imaging guided percutaneous drainage of the mediastinal abscess combined with stenting. We report a patient who presented with esophageal perforation complicated with a mediastinal abscess that was treated successfully with an imaging guided percutaneous drainage of the mediastinal abscess. This case is to emphasize on the fact that endoscopic stent placement is safe and effective for esophageal perforations. Percutaneous CT-guided drainage of associated mediastinal abscesses is an uncommon procedure, but the results suggest that it is associated with high technical and clinical success rates. There should be increased involvement of interventional radiology in the management of those cases.
\end{abstract}

Keywords: Esophageal perforation, mediastinal abscess, CT guided drainage

Esophageal perforation is a rare but potentially fatal surgical emergency with high mortality rates. Factors contributing to high morbidity and a mortality rate of $>20 \%$ include proximity of vital organs, difficulty to access the esophagus, the lack of a strong serosa and complex blood supply of itself (1-3). Perforation can be either idiopathic or iatrogenic which is commonly a result of endoscopic procedures (esophagectomy, emetogenic, or food impaction). Spontaneous rupture without pre-existing pathology of the esophagus has been reported in about $15 \%$ of the cases (4).

Released online in J-STAGE as advance publication August 20, 2019.

*Address correspondence to:

Dr. Azka Latif, CHI Health, Creighton University, 7500 Mercy Road, Omaha, NE 68124, USA.

E-mail: azkalatif@creighton.edu
A 45-year-old male presented to the emergency department with sudden onset of throat spasms, and dysphagia after accidental ingestion of a bone fragment while eating a T-bone steak. Initial vitals showed sinus tachycardia and significant distress on physical exam. A computed tomography (CT) of chest showed extravasation of contrast into the mediastinum and pneumomediastinum. Esophagogram showed esophageal perforation and leak $10 \mathrm{~cm}$ proximal to gastroesophageal (GE) junction. Endoscopy was performed, bone was retrieved with placement of covered esophageal stent. It showed a non-bleeding perforation with adjacent mucosal erythema. On day7, patient had high fevers with up-trending white blood cell count (WBC: $25 \mathrm{k} / \mathrm{uL}$ ). CT chest showed pneumomediastinum with periesophageal abscess extending from carina to GE junction surrounding stent (Figure 1A and 1B). 
A
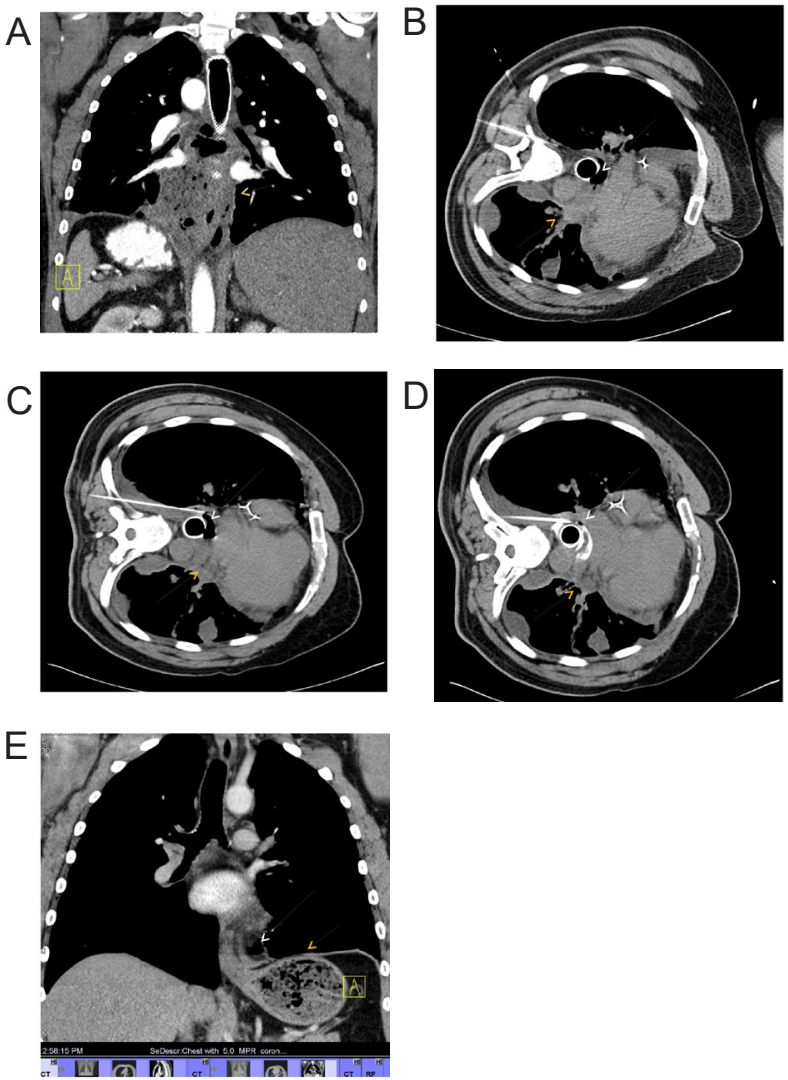

Figure 1. Computed tomography of chest showing (A) pneumomediastinum with periesophageal abscess extending from carina to GE junction (Yellow arrow), (B) pneumomediastinum (white arrow) with periesophagea abscess (yellow arrow), (C) advancement of pigtail catheter into periesophageal abscess, (D) advancement and dilatation of pigtail catheter into periesophageal and mediastinal abscess, and (E) complete resolution of abscess.

At that point interventional radiology performed CTguided drainage of mediastinal abscess with seldingertechnique and placement of a left posterior suction drain. A 25-gauge Chiba needle was advanced into the collection with CT guidance. With the needle tip in the collection, the inner trocar needle was removed, and a fluid sample was obtained for microbiologic analysis. Thereafter, a guide wire was advanced into the abscess. The percutaneous tract was then serially dilated with serial dilators, after which a locking pigtail catheter was then advanced over the guide wire and into the collection (Figure 1C and 1D). At the time of initial drainage, all purulent material was aspirated to completion and flushed with 5-10 mL sterile saline solution to ensure complete drainage. The catheters were then secured to the skin with a retention device and placed to gravity drainage. Following drainage, WBC trended down, followed by complete resolution of abscess (Figure 1E). Stent was removed followed by complete recovery.

The principles of management of esophageal perforation include broad spectrum IV antibiotics, gastric decompression, control of ongoing leak, surgical debridement of infected tissue and drainage of mediastinal cavity especially with acute septicemia. Operative repair for esophageal perforation has been gold standard treatment for an acute perforation, however, paradigm shift towards the use of selfexpandable metallic and plastic stents has been seen especially in the absence of acute septicemia and with limited mediastinal or pleural contamination. Complications of self-expandable stents include stent migration, leakage, stent perforation or bleeding. Mediastinal abscess is one of the leading causes of mortality after esophageal perforation which requires adequate drainage (5). Imaging guided percutaneous drainage of the mediastinal abscess combined with stenting is an emerging alternative treatment to open drainage with potentially high technical and clinical success. In 2011 Arellano et al., conducted a trial in patients with mediastinal abscess who underwent CT guided drainage $(n=23)$ over a period of 10 years. Out of 23 patients, 22 patients had complete resolution of abscess and they didn't require any surgical intervention with a success rate of $95.6 \%$ (6).

In our patient successful drainage was performed with less invasive seldinger-technique, with the patient scanned in right-lateral-decubitus. Patient positioning was determined based on the shortest and safest route to the abscess. Images were then analyzed to determine the safest percutaneous route to the abscess that avoided the esophagus, the lung, or the internal mammary or intercostal arteries. Despite adequate safety and efficacy of stents in acute esophageal perforation, a head to head trial with surgical repair is still lacking.

Ben-David $\mathrm{K}$ et al., conducted a retrospective review of acute esophageal perforation cases from 2007 through $2013(n=76)$. All patients were treated within first 24 hours of presentation with a removable covered esophageal stent. Median length of stay at ICU and hospital was 3 and 10 days respectively with median hospital charges of $\$ 85,945$. The mortality rate was $1.3 \%$ in first 30 days (7). Likewise, Richard $\mathrm{K}$ freeman et al., evaluated 60 patients who had either stent placement or surgical intervention for iatrogenic esophageal perforation from 2009 through 2012. They compared the cost and the outcomes (mortality, morbidity, length of hospital stay) within 2 cohorts. Their results showed both modalities of treatment were equally effective, however, stent placement was seen to be more cost effective with less mortality and morbidity rates. They noticed a significant difference in morbidity $(17 \%$ vs. $43 \%, p=0.02)$, mean length of hospital stay ( 6 vs. 11 days, $p=0.0007$ ), time for oral intake (3vs. 8 days, $p=0.0004)$, and cost $(\$ 91,000$ vs. 142,000 , $p<0.0001)$ in patients who had stent placement in comparison to the ones getting surgical repair (8).

Further head to head clinical trials are required to compare esophageal stents and CT guided drainage of mediastinal abscess with open surgical repair to reduce overall morbidity, mortality and cost of hospital. 


\section{References}

1. Ryom P, Ravn JB, Penninga L, Schmidt S, Iversen MG, Skov-Olsen P, Kehlet H. Aetiology, treatment and mortality after oesophageal perforation in Denmark. Dan Med Bull. 2011; 58:A4267.

2. Vidarsdottir H, Blondal S, Alfredsson H, Geirsson A, Gudbjartsson T. Oesophageal perforations in Iceland: A whole population study on incidence, aetiology and surgical outcome. Thorac Cardiovasc Surg. 2010; 58:476480 .

3. Bhatia P, Fortin D, Inculet RI, Malthaner RA. Current concepts in the management of esophageal perforations: A twenty-seven year Canadian experience. Ann Thorac Surg. 2011; 92:209-215.

4. Søreide JA, Viste A. Esophageal perforation: Diagnostic work-up and clinical decision-making in the first 24 hours. Scand J Trauma Resusc Emerg Med. 2011; 19:66.

5. White CS, Templeton PA, Attar S. Esophageal perforation:
CT findings. AJR Am J Roentgenol. 1993; 160:767-770.

6. Arellano RS, Gervais DA, Mueller PR. Computed tomography-guided drainage of mediastinal abscesses: clinical experience with 23 patients. J Vasc Interv Radiol. 2011; 22:673-677.

7. Ben-David K, Behrns K, Hochwald S, Rossidis G, Caban A, Crippen C, Caranasos T, Hughes S, Draganov P, Forsmark C, Chauhan S, Wagh MS, Sarosi G. Esophageal perforation management using a multidisciplinary minimally invasive treatment algorithm. J Am Coll Surg. 2014; 218:768-774.

8. Freeman RK, Herrera A, Ascioti AJ, Dake M, Mahidhara RS. A propensity-matched comparison of cost and outcomes after esophageal stent placement or primary surgical repair for iatrogenic esophageal perforation. J Thorac Cardiovasc Surg. 2015; 149:1550-1555.

(Received June 19, 2019; Revised August 8, 2019; Accepted August 10, 2019) 